\title{
A CASE OF DEFINITIVE JAW RECONSTRUCTION FOLLOWING A BOMB INJURY RECEIVED IN NORTHERN IRELAND
}

\author{
Major J. G. JOHNSTON, L.R.C.P.I., F.R.C.S.(Ed.), R.A.M.C. \\ Major L. J. KESSEL, B.D.S., F.D.S., R.C.S.(Eng.), R.A.D.C. \\ Military Hospital, Tidworth
}

SUMMARY: The case illustrated certain aspects of trauma surgery. Patients with fractures of the facial bones are usually conscious and do not present signs of severe shock, nevertheless they must be treated as seriously ill patients during radiographic and other examinations as their airway is at risk.

Initial surgery should be life-saving and a tracheostomy should be carried out whenever a missile traverses the floor of the mouth, whether or not there are concomitant mandibular fractures (Yao 1972).

Reparative surgery should be carried out at a later date as the primary aim is a live patient with a good airway.

\section{Introduction}

Mandibular injuries due to missiles, with resultant bone loss, are not uncommon in military personnel. Many methods have been described in the literature to re-establish continuity (Szmyd and Morgan 1969, Archer 1966, Rowe and Dilley 1968). The authors decided on the described technique, illustrated in this case, as being simple, efficient and as successful as some of the more complicated methods.

\section{Case history}

On 16 August 1971, Sergeant P.W. was involved in a "Claymore mine " explosion whilst commanding a Ferret scout car. He received a penetrating wound from a metal fragment-a bolt head-which entered the lower border of the right mandible and finally lodged in the soft tissue of the left cheek, resulting in compound comminuted fracture of both mandibular bodies.

The patient had the presence of mind to hold his jaw forward, thus maintaining his airway. The only time his airway was endangered was when he was placed on his back in hospital for radiography. This bears out the well known saying that " if you are looking towards heaven you will soon be there".

The initial treatment at a local hospital in Ulster consisted of iracheostomy, debridement and cleansing of the facial wounds, removal of the retained bolt head and ligation of the right facial artery. Fractured teeth and loose bone fragments were removed and the mucosa sutured. The anterior mandibular fragment was immobilised using eyelet and interdental wires (Fig. 1). A course of antibiotics was prescribed.

On 23 August 1971, the tracheostomy tube was removed and the patient transferred the following week to a hospital in England, where the eyelet and interdental svires were replaced by sectional acrylic cap splints. 


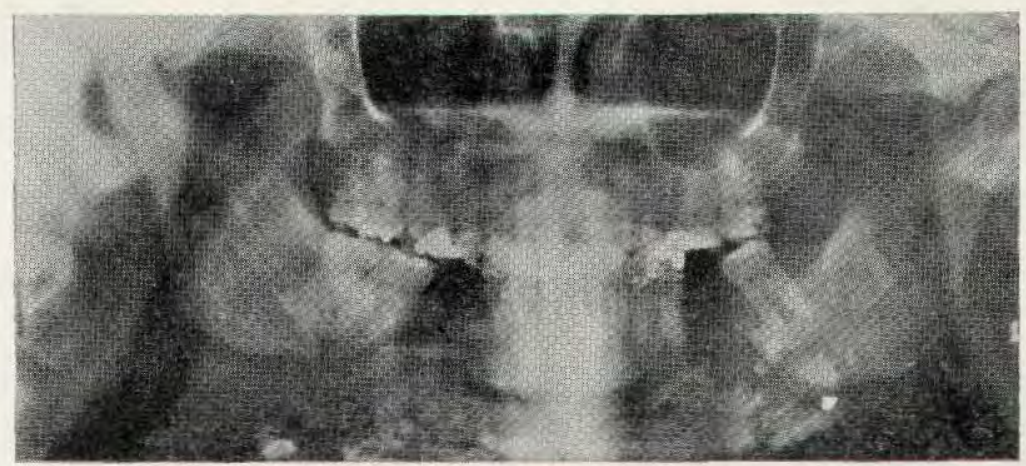

Fig. 1. Fractured mandible with anterior fragment fixation.

At the end of three months the fracture of the left body had healed well, however, there was clinical and radiological evidence of non-union on the right side. This most probably occurred as a result of difficulties experienced in adequate fixation of the bony fragment initially, coupled with possible introduction of infection via the tooth in the fracture line.

At this time the patient came under the care of the authors who decided to restore the continuity of the right body of the mandible by a full thickness iliac crest bone graft. Prior to this the lower right second molar, the tooth on the fracture line, was extracted under local anaesthesia. From study models articulated in a pre-determined occlusion, upper and lower cast silver splints were constructed and cemented into position.

On 23 February 1972, under naso-endo-tracheal anaesthesia, a full thickness bone graft was cut from the right iliac crest. Elastic ligatures were applied to immobilise the mandible to the maxilla. Through a submandibular incision the fracture line was exposed and the bone ends freshened. Lap joints were cut to receive the bone graft, which had been shaped to the required contour, this was then wired into position.

During the procedure it was necessary to extract the $\overline{8} /$ along with a loose fragment of bone to which it was attached. The elastic ligatures were removed, the $\overline{8} \mid$ socket was sutured intra orally and the throat pack removed. The ligatures were then replaced. The incisions were closed in layers, with suction drainage. The patient was prescribed Ampiclox $500 \mathrm{mg}$ q.d.s. for two weeks.

Postoperatively there was considerable facial swelling. The drains were removed after 48 hours. Immediate postoperative radiographs showed the graft in good position. One week later on the 2 nd March 1972, the elastic ligatures were replaced by $0.35 \mathrm{~mm}$ tie wires.

On 5 April 1972 when there was clinical and radiological evidence of union the splints were removed, movement and exercises commenced. To improve the occlusion the carious $88 \mid 7$ were extracted.

The patient made excellent progress and one year after surgery he could open his mouth to $38 \mathrm{~mm}$ (Fig. 2) and perform all jaw movements well. A radiograph at this time showed sound union (Fig. 3). He still had some scarring from the entry wound and the submandibular incision, but as these showed no evidence of keloid formation and were resolving satisfactorily no further plastic procedures were considered necessary. 


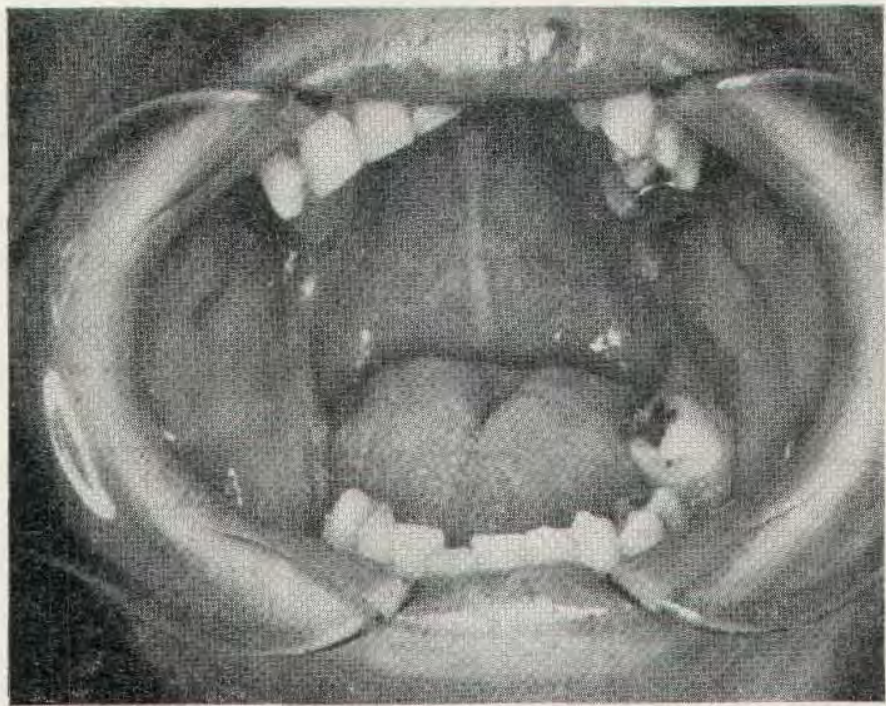

Fig. 2. Patient with mouth open to $38 \mathrm{~mm}$ one year after surgery.

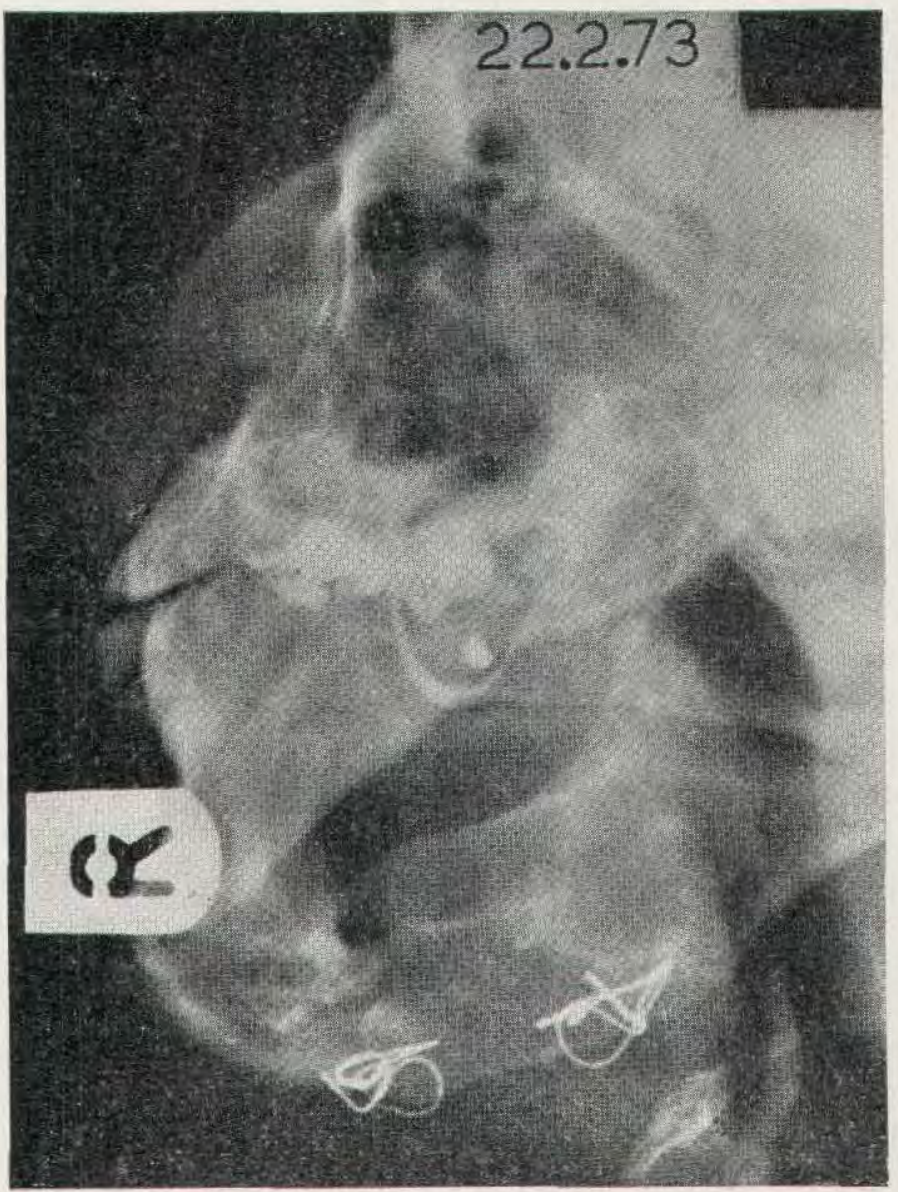

Fig. 3. Lateral oblique radiograph on 22 February 1973 showing union. 


\section{REFERENCES}

ARCHER, W. H. (1966), Oral Surgery. 4th Edition. Henry Kimpton. London.

Rowe, N. L. and Killey, H. C. (1963). Fractures of the Facial Skeleton. 2nd ed. E. \& S. Livingstone. Edinburgh.

Szmyd, L. and Morgan, H. H. (1969). Anterior Ramus Grafts of the mandible. J. Oral Surg. $27,132$.

\section{Army Insurance Scheme has 9,000 Members}

More than 9,000 soldiers from units world wide have joined ADAT - the Army Dependants Assurance Trust - since it was launched last September, and the dependants of six who have since died or been killed will receive a total of over $£ 147,000$. One dependant, the father of a Gunner shot in Northern Ireland, will get $£ 64,000$.

The best response to the scheme has come from the Royal Highland Fusiliers, the Argyll and Sutherland Highlanders and the Scottish Infantry Depot at Glencorse. Each has over 200 members.

Close behind with more than 100 members each, are the Queen's Own Hussars, 2nd Bn Scots Guards, 1st Bn Royal Irish Rangers, 12th Light Air Defence Regiment Royal Artillery, 94th Locating Regiment Royal Artillery, 32nd Engineer Regiment and 9th Signal Regiment.

Two members are Sappers well-known for living dangerously, Major Neil Carlier, a skipper of British Soldier, the Army entry in the Round the World Yacht Race, joined before sailing. Major John Blashford-Snell, leader of the Trans-Americas Expedition of 1972 who is shortly to lead the Zaire River Expedition, has also signed up.

A 30 p weekly prenium, on which tax relief can be claimed, buys a unit which assures $£ 10$ a week to a dependant from the time of a soldier's death from any cause until he or she would have reached age 55 . A premium of $50 \mathrm{p}$ weekly continues the income for a further five years. Anyone engaged to be married to an ADAT member is a dependant.

Enquiries should be made at your Unit Pay Office and not to the Journal of the R.A.M.C. 